\title{
Elastic band resistance training influences transforming growth factor- $\beta$ receptor I mRNA expression in peripheral mononuclear cells of institutionalised older adults: the Vienna Active Ageing Study (VAAS)
}

Barbara Schober-Halper ${ }^{1}$, Marlene Hofmann'1, Stefan Oesen ${ }^{1}$, Bernhard Franzke1, Thomas Wolf², Eva-Maria Strasser ${ }^{3}$, Norbert Bachl ${ }^{2}$, Michael Quittan ${ }^{3}$, Karl-Heinz Wagner ${ }^{1,4}$ and Barbara Wessner ${ }^{1,2^{*}}$ (D)

\begin{abstract}
Background: Ageing, inactivity and obesity are associated with chronic low-grade inflammation contributing to a variety of lifestyle-related diseases. Transforming growth factor- $\beta$ (TGF- $\beta$ ) is a multimodal protein with various cellular functions ranging from tissue remodelling to the regulation of inflammation and immune functions. While it is generally accepted that aerobic exercise exerts beneficial effects on several aspects of immune functions, even in older adults, the effect of resistance training remains unclear. The aim of this study was to investigate whether progressive resistance training (6 months) with or without nutritional supplementation (protein and vitamins) would influence circulating C-reactive protein and TGF- $\beta$ levels as well as TGF- $\beta$ signalling in peripheral mononuclear cells (PBMCs) of institutionalised adults with a median age of 84.5 (65.0-97.4) years.

Results: Elastic band resistance training significantly improved performance as shown by the arm-lifting test ( $p=0.007)$, chair stand test $(p=0.001)$ and 6 -min walking test $(p=0.026)$. These results were paralleled by a reduction in TGF- $\beta$ receptor I (TGF-BRI) mRNA expression in PBMCs $(p=0.006)$, while circulating inflammatory markers were unaffected. Protein and vitamin supplementation did not provoke any additional effects. Interestingly, muscular endurance of upper and lower body and aerobic performance at baseline were negatively associated with changes in circulating TGF- $\beta$ at the early phase of the study. Furthermore, drop-outs of the study were characterised not only by lower physical performance but also higher TGF- $\beta$ and TGF- $\beta$ RI mRNA expression, and lower miRNA-21 expression.

Conclusions: Progressive resistance training with elastic bands did not influence chronic low-grade inflammation but potentially affected TGF- $\beta$ signalling in PBMCs through altered TGF- $\beta R I$ mRNA expression. There appears to be an association between physical performance and TGF- $\beta$ expression in PBMCs of older adults, in which the exact mechanisms need to be clarified.
\end{abstract}

Keywords: Vienna Active Ageing Study (VAAS), TGF- $\beta$ pathway, microRNA, Chronic inflammation, Inflammageing, Strength training

\footnotetext{
* Correspondence: barbara.wessner@univie.ac.at

${ }^{1}$ Research Platform Active Ageing, University of Vienna, Althanstraße 14, 1090 Vienna, Austria

${ }^{2}$ Department of Sports and Exercise Physiology, Centre for Sport Science and

University Sports, University of Vienna, Auf der Schmelz 6, 1150 Vienna,

Austria

Full list of author information is available at the end of the article
} 


\section{Background}

Population ageing resulting from a higher life expectancy concomitant with a decline in fertility will lead to a global increase in the proportion of people over the age of 60 years from $12 \%$ in 2015 to $22 \%$ by 2050 [1]. With higher ages, the prevalence of cardiovascular, metabolic and neurodegenerative disorders and cancer is increased. It has been shown that many of these conditions are related to compromised homeostasis between proper activation of the immune system and its resolution, leading to a limited response to pathogens and vaccines and a chronic inflammatory state $[2,3]$.

Transforming growth factor- $\beta$ (TGF- $\beta$ ) is a multifunctional protein involved in the regulation of cell proliferation, extracellular matrix production, inflammation and immune functions [4]. Higher circulating levels of TGF$\beta$ are related to obesity with impaired insulin sensitivity [5], cardiovascular diseases among individuals with higher C-reactive protein (CRP) levels [6], type II diabetes $[7,8]$, and a higher age [9]. TGF- $\beta$ interacts with several cell types by binding to membrane serine/ threonine kinase receptors, TGF- $\beta$ receptor I (TGF- $\beta$ RI; also known as ALK5) and TGF- $\beta$ RII, initiating diverse cellular responses [10]. An approach to modulate TGF- $\beta$ signalling is to alter the expression of its receptors. It has become evident that microRNAs (miRNAs) regulate thousands of human genes by either mRNA degradation or suppression of mRNA translation [11]. A recent investigation estimated that $84-89 \%$ of miRNA-induced suppression of gene expression is the result of degradation of target mRNAs [12]. Currently, close to 1900 human miRNA precursors are listed in the miRBase registry, which give rise to 2588 mature miRNAs [13, 14]. One of these miRNAs, miRNA-21, plays a crucial role in a plethora of biological functions and diseases including the development of cancer, cardiovascular diseases and inflammation [15]. Interestingly, miRNA-21 targets both TGF- $\beta$ RI and TGF- $\beta$ RII [16], and overexpression of miRNA-21 is associated with elevated levels of proinflammatory cytokines in a dominant-negative TGF- $\beta$ RII mouse model [17].

Regular physical activity offers protection against, and may be a useful treatment for, a wide variety of chronic diseases associated with low-grade inflammation [18]. In particular, endurance exercise training combined with dietary weight loss strategies have been shown to decrease the chronic inflammatory state associated with obesity and old age $[19,20]$. Resistance training prevents or counteracts age-related loss of muscle mass and functions [21, 22], but there is an ongoing discussion whether this type of exercise alters the chronic inflammatory state associated with ageing [23-25].

In the Vienna Active Ageing Study (VAAS), we previously showed that resistance training using elastic bands for 6 months leads to an increase in functional performance of the lower and upper extremities and improves muscle quality in older people [22, 26]. Furthermore, we detected higher CRP levels and lower TGF- $\beta$ RI and TGF- $\beta$ RII expression in peripheral blood mononuclear cells (PBMCs) of older women compared with younger women [27]. Therefore, the aim of this sub-study of the VAAS was to investigate whether progressive resistance training alone or in combination with a nutritional supplement containing protein and vitamins influenced expression of TGF- $\beta$, its receptors, and/or miRNA-21 in older institutionalised people.

\section{Results}

\section{Subject characteristics}

A total of 230 potential participants were screened for eligibility, and 117 participants (89 women and 12 men) agreed to participate in the VAAS. The participants were randomised into intervention groups: cognitive training (CT), resistance training (RT), and resistance training plus nutritional supplementation (RTS) (Fig. 1). Blood samples were available from 95 participants (84 women and 11 men). To prevent any potential interference by acute inflammatory processes, we excluded all subjects with CRP levels above $10 \mathrm{mg} / \mathrm{L}$ at any time point as done previously $[28,29]$. Finally, data from 88 participants (77 women and 11 men) with a median age of $84.5(65.2-97.4)$ years and a median body mass index (BMI) of $28.9(18.1-50.0) \mathrm{kg} / \mathrm{m}^{2}$ were included in the current study (Fig. 1). No differences between study groups with respect to age, gender, anthropometric data and health status were detected at baseline, whereas leukocyte numbers differed significantly between intervention groups $(p=0.002)$. Post-hoc analyses revealed that subjects from the RT group had lower leukocyte numbers than those from the CT group $(+28 \%$, $p=0.002)$ and the RTS group $(+19 \%, p=0.039)$, which was owing to lower numbers of neutrophils (CT: $+51 \%$, $p<0.001$; RTS: $+33 \%, p=0.092)$. Circulating inflammatory markers (hs-CRP and TGF- $\beta$ ) and mRNA expression of TGF- $\beta$, its receptors and miRNA-21 in PBMCs (lymphocytes and monocytes) did not differ between groups at baseline (Table 1).

\section{Dropout analysis}

During 6 months of intervention, 18 women and 3 men $(27 \%)$ left the study because of several reasons (loss of interest or acute medical reasons such as joint pain or cardiological issues). The dropout rate did not differ between groups. In addition, age, sex, and existing comorbidities in general were not related to adherence to the study. Only the number of participants diagnosed for hyperlipidaemia was higher in finishers compared with the dropouts $(p=0.016)$. Baseline performance appeared to be related to study adherence because 
Vienna Active Ageing Study Population $(n=117)$

No baseline data $(n=22)$

CRP levels $>10 \mathrm{mg} / \mathrm{L}$ at any time point $(n=7)$

Study population included in the current study $(n=88)$

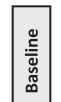

Cognitive Training (CT) $(n=30)$

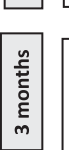

CT $(n=23)$

Drop out $(n=7)$

Medical reason $(n=2)$

Loss of interest $(n=5)$

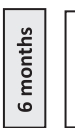

CT $(n=20)$

Medical reason $(n=1)$

Loss of interest $(n=2)$
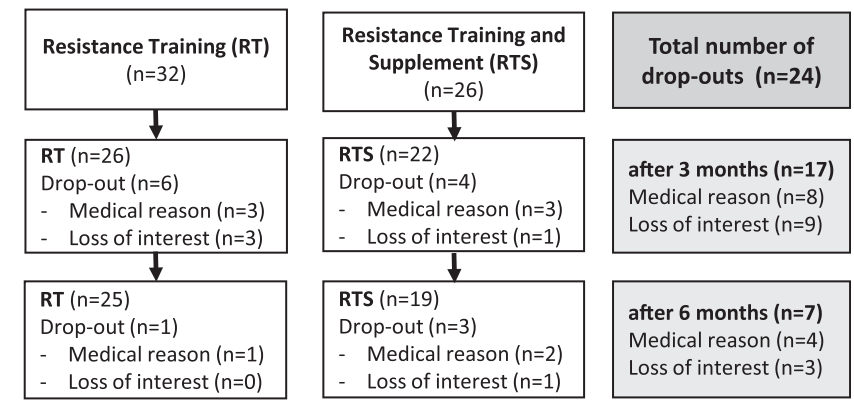

Fig. 1 Participant flow

dropouts had lower aerobic (6MWT: $-19 \%, p=0.020$ ) and chair stand $(-13 \%, p=0.015)$ performance than finishers of the study. Strength $(p=0.608)$ and muscular endurance $(p=0.924)$ of the upper extremities were not different between finishers and dropouts. The observed differences also became evident in some of the TGF- $\beta$ related parameters because TGF- $\beta(+106 \%, p=0.016)$ and TGF- $\beta$ RI $(+237 \%, p<0.001)$ mRNA expression was higher in dropouts, while miRNA-21 expression was lower $(-65 \%, p<0.001)$ (Table 2). As a consequence we performed a per-protocol analysis by excluding the dropouts from all subsequent analyses (Tables 3 and 4).

\section{Resistance training improves physical performance of older subjects}

We have previously shown that resistance training intervention specifically improved muscular endurance (chair stand and arm-lifting tests), while isometric strength (handgrip test) and aerobic capacity (6-min walking test; 6MWT) increased similarly in CT, RT and RTS groups [22]. Because the current study included just a subset of the original study population, the data on physical performance were re-analysed. At baseline, no differences in any of the physical fitness parameters were observed between intervention groups $(p>0.05)$. Similar to the previous results, chair stand performance was increased in the RT group (3 months: $+18 \%, p=0.041 ; 6$ months: $+27 \%$, $p=0.001)$ and RTS group (6 months: $+15 \%, p=0.017$ ). Arm-lifting performance was enhanced in RT and RTS groups only after 6 months (RT: $+24 \%, p=0.007$; RTS $+61 \%, p=0.007)$. While handgrip strength was unaltered over time in all intervention groups (CT: $p=0.454$;
RT: $p=0.238$, RTS: $p=0.810$ ), aerobic performance during the 6MWT was slightly improved in the RT group after 6 months (+9 \%, $p=0.026)$ but not in the CT or RTS groups (CT: $p=0.959$, RTS: $p=0.080$ ) (data not shown).

\section{Effects of interventions on leukocyte subpopulations and circulating inflammatory markers}

Except for an adaptation of the leukocyte numbers in the RT group (overall: $p=0.001 ; 3$ months: $p=0.166$; 6 months: $p=0.001 ;+7 \%)$ caused by an increase in neutrophils (overall: $p=0.011 ; 3$ months: $p=0.166$; 6 months: $p=0.010+22 \%$ ), we did not detect any other alterations in leukocyte, lymphocyte, monocyte or granulocyte counts. Similarly, the circulating levels of TGF- $\beta$ and hs-CRP remained unchanged (Table 3 ).

\section{Influence of interventions on intracellular TGF- $\beta$ and TGF- $\beta$ receptor mRNA expression, and miRNA-21 expression}

The mRNA expression of TGF- $\beta$, TGF- $\beta$ RI, TGF- $\beta$ RII and miRNA-21 in PBMCs did not differ between groups at any time point. Resistance training led to a significant decrease in TGF- $\beta$ RI mRNA levels $(p=0.006)$. Post-hoc analyses revealed that the initial decrease at 3 months $(-27 \%, p=0.015)$ was reversed at 6 months $(p=0.117)$. Interestingly, this decrease could not be confirmed in the RTS group, although the median level decreased similarly to the RT group. Intracellular TGF- $\beta$ and TGF- $\beta$ RII mRNA expression, and miRNA-21 expression, were not influenced by any of the interventions (Table 4).

Because resistance training only led to marginal changes in the TGF- $\beta$ signalling pathway, we examined whether 
Table 1 Baseline characteristics

\begin{tabular}{|c|c|c|c|c|c|}
\hline & All $(n=88)$ & $\mathrm{CT}(n=30)$ & $\mathrm{RT}(n=32)$ & RTS $(n=26)$ & $P$-value \\
\hline Gender [female/male] & $77 / 11$ & $25 / 5$ & $28 / 4$ & $24 / 2$ & 0.602 \\
\hline Age [years] & $84.5(65.0-97.4)$ & $84.5(69.4-97.4)$ & $84.4(71.7-93.2)$ & $84.3(65.0-92.2)$ & 0.864 \\
\hline BMI $\left[\mathrm{kg} / \mathrm{m}^{2}\right]$ & $28.9(18.1-50.0)$ & $29.8(18.1-36.9)$ & $28.2(22.7-40.2)$ & $27.9(22.9-50.0)$ & 0.741 \\
\hline Obesity [n (\%)] & $32(36.8 \%)$ & $14(46.7 \%)$ & $8(25.0 \%)$ & $10(35.7 \%)$ & 0.235 \\
\hline Hyperlipidaemia [n (\%)] & $32(36.4 \%)$ & $9(30.0 \%)$ & $10(31.3 \%)$ & $13(46.4 \%)$ & 0.226 \\
\hline Diabetes Type II [n (\%)] & $14(15.9 \%)$ & $6(20 \%)$ & 7 (21.9\%) & $1(3.6 \%)$ & 0.132 \\
\hline Hypertension [n (\%)] & 70 (79.5 \%) & $26(86.7 \%)$ & 27 (84.4 \%) & $17(60.7 \%)$ & 0.100 \\
\hline Cardiac diseases [n (\%)] & $27(30.7 \%)$ & $12(40.0 \%)$ & 9 (28.1\%) & $6(21.4 \%)$ & 0.362 \\
\hline Osteoporosis [n (\%)] & 35 (39.8 \%) & $12(40.0 \%)$ & $12(37.5 \%)$ & $11(39.3 \%)$ & 0.933 \\
\hline History of cancer [n (\%)] & $12(13.6 \%)$ & $5(16.7 \%)$ & $4(12.5 \%)$ & $3(10.7 \%)$ & 0.833 \\
\hline \multicolumn{6}{|c|}{ Leukocyte subpopulations and circulating biomarkers } \\
\hline Leukocytes $\left[\times 10^{9}\right.$ cells/L] & $6.6(3.3-13.0)$ & $7.4(4.9-10.3)^{*}$ & $5.8(3.1-9.8)$ & $6.9(4.4-13.3)^{*}$ & 0.002 \\
\hline 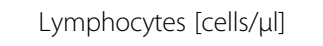 & $1990(930-4930)$ & $1985(910-3510)$ & $1835(830-3330)$ & $2200(1460-4700)$ & 0.085 \\
\hline 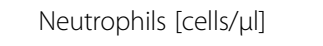 & 3695 (1530-9860) & $4414(2410-6630)^{*}$ & $2931(1530-6800)$ & 3889 (2370-9860) & $<0.001$ \\
\hline 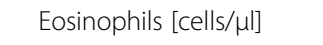 & $200(10-740)$ & $225(36-620)$ & $160(10-740)$ & $220(10-470)$ & 0.135 \\
\hline Basophils $[$ cells/ $/ \mu l]$ & $40(10-111)$ & $45(10-111)$ & $35(10-190)$ & $35(10-90)$ & 0.397 \\
\hline 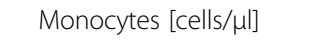 & $560(250-910)$ & $587(72-950)$ & $520(260-860)$ & $545(320-960)$ & 0.189 \\
\hline $\mathrm{hs}-\mathrm{CRP}[\mathrm{mg} / \mathrm{L}]$ & $1.95(0.3-7.9)$ & $2.1(0.5-7.9)$ & $1.9(0.3-7.6)$ & $1.9(0.6-6.7)$ & 0.918 \\
\hline TGF- $\beta[\mu \mathrm{g} / \mathrm{L}]$ & $33.3(16.7-73.7)$ & $38.2(18.7-73.7)$ & $32.8(16.7-55.4)$ & $32.1(21.0-51.2)$ & 0.083 \\
\hline \multicolumn{6}{|l|}{ PBMC gene expression } \\
\hline TGF- $\beta / G A P D H ~[-]$ & $0.85(0.06-3.36)$ & $0.48(0.23-2.66)$ & $0.60(0.21-2.52)$ & $0.58(0.06-3.36)$ & 0.725 \\
\hline TGF- $\beta$ RI/GAPDH [-] & $2.05(0.14-28.82)$ & $1.99(0.14-22.39)$ & $2.04(0.69-19.25)$ & $2.11(0.29-28.81)$ & 0.990 \\
\hline TGF- $\beta R I I / G A P D H[-]$ & $1.67(0.51-15.85)$ & $1.54(0.66-7.79)$ & $1.60(0.66-14.85)$ & $1.79(0.51-10.80)$ & 0.714 \\
\hline miRNA-21 [copies/pg] & $2400(57-4720)$ & $2920(343-4500)$ & $2120(57-4720)$ & $2350(550-4590)$ & 0.765 \\
\hline
\end{tabular}

Data are expressed as medians (min-max); Group differences were detected using $X^{2}$ or Kruskal-Wallis tests and if significant, followed by Bonferroni-corrected post-hoc analyses $\left({ }^{*} p<0.05\right.$ vs. RT); significant differences are marked in bold

Abbreviations: $C T$ cognitive training, RT resistance training, RTS resistance training plus supplement, $P B M C$ peripheral blood mononuclear cell, $h s-C R P$ high sensitive C-reactive protein, TGF- $\beta$ transforming growth factor- $\beta$, TGF- $\beta R$ TGF- $\beta$ receptor, GAPDH glyceraldehyde 3-phosphate dehydrogenase, miR-21 microRNA-21

different components of physical fitness (strength, muscular endurance and aerobic performance) at baseline influenced the TGF- $\beta$ signalling response (difference between 3 or 6 months and baseline values). While isometric handgrip strength was not associated with alterations in TGF- $\beta$ related parameters, muscular endurance and aerobic performance at baseline were negatively associated with changes in circulating TGF- $\beta$ levels after 3 months (chair rise test: $\rho=-0.349, p=0.003$, arm-lifting test: $\rho=-0.352$, $p=0.024$; 6MWT: $\rho=-0.308, p=0.009$ ), but chair stand performance was positively associated with changes in TGF- $\beta$ RII mRNA expression $(\rho=0.254, \quad p=0.033)$ (Table 5).

\section{Discussion}

The aim of the current study was to investigate the effects of progressive resistance training alone and in combination with a nutritional supplement enriched with protein and vitamins on systemic inflammation and TGF- $\beta$ signalling in PBMCs of institutionalised, but independent older people. Circulating TGF- $\beta$ and hs-CRP levels as well as intracellular TGF- $\beta$ gene expression were not influenced by elastic band resistance training. Interestingly, TGF- $\beta$ RI, but not TGF- $\beta$ RII, gene expression was reduced in the RT group after 3 months and returned to baseline levels thereafter.

It is well known that regular endurance training reduces the chronic proinflammatory state caused by ageing and physical inactivity [30, 31]. Adipose tissue appears to play a substantial role in this scenario because it is a major source of several hormones and cytokines [32]. In particular, visceral fat depots and the macrophages within these depots release proinflammatory cytokines such as interleukin-6 (IL-6), tumour necrosis factor- $\alpha$ (TNF- $\alpha$ ) and TGF- $\beta 1$ [33]. The increase in energy expenditure caused by enhanced physical activity reduces body fat, thereby influencing the capacity to produce and release proinflammatory mediators [33]. Recommended strategies to lose weight and body fat include aerobic exercise training combined with 
Table 2 Baseline differences between drop-outs and finishers

\begin{tabular}{|c|c|c|c|c|}
\hline & Total $(n=88)$ & Dropouts $(n=21)$ & Non-Dropouts $(n=67)$ & $p$-value \\
\hline Gender [female/male] & $77 / 11$ & $18 / 3$ & $59 / 8$ & 0.777 \\
\hline Age [years] & $84.5(65.0-97.4)$ & $85.2(69.4-92.2)$ & $84.2(65.0-97.4)$ & 0.282 \\
\hline BMI $\left[\mathrm{kg} / \mathrm{m}^{2}\right]$ & $28.9(18.1-50.0)$ & $28.3(18.1-43.7)$ & $30.7(23.4-50.0)$ & 0.094 \\
\hline hs-CRP [mg/L] & $1.9(0.3-7.9)$ & $2.0(0.8-7.9)$ & $1.9(0.3-7.6)$ & 0.413 \\
\hline \multicolumn{5}{|l|}{ TGF- $\beta$ signalling } \\
\hline TGF- $\beta[\mu \mathrm{g} / \mathrm{L}]$ & $33.3(16.7-73.7)$ & $39.3(22.5-58.0)$ & $32.8(16.7-73.7)$ & 0.178 \\
\hline TGF- $\beta / G A P D H[-]$ & $0.53(0.06-3.36)$ & $1.07(0.21-3.36)$ & $0.52(0.06-2.66)$ & 0.016 \\
\hline TGF- $\beta$ RI/GAPDH [-] & $2.05(0.14-28.81)$ & $6.41(1.31-28.81)$ & $1.90(0.14-22.39)$ & $<0.001$ \\
\hline TGF- $\beta$ RII/GAPDH [-] & $1.67(0.51-14.85)$ & $3.00(0.91-10.80)$ & $1.59(0.51-14.85)$ & 0.099 \\
\hline miR-21 [copies/pg RNA] & $2400(57-5720)$ & $979(498-3640)$ & $2815(57-4720)$ & $<0.001$ \\
\hline \multicolumn{5}{|l|}{ Co-morbidities } \\
\hline Obesity [n (\%)] & 32 (36.4 \%) & 10 (47.6 \%) & $22(32.8 \%)$ & 0.162 \\
\hline Hyperlipidemia [n (\%)] & $32(36.4 \%)$ & $3(14.2 \%)$ & $29(43.3 \%)$ & 0.016 \\
\hline Diabetes Type II [n (\%)] & 14 (15.9\%) & $3(14.3 \%)$ & $11(16.4 \%)$ & 0.816 \\
\hline Hypertension [n (\%)] & $70(79.5 \%)$ & 17 (81.0 \%) & $53(79.1 \%)$ & 0.855 \\
\hline Cardiac diseases [n (\%)] & 27 (30.7 \%) & $7(33.3 \%)$ & $20(29.9 \%)$ & 0.763 \\
\hline Osteoporosis [n (\%)] & 35 (39.8 \%) & $9(42.9 \%)$ & $26(38.8 \%)$ & 0.741 \\
\hline History of cancer [n (\%)] & $12(13.6 \%)$ & $3(14.3 \%)$ & 9 (13.4\%) & 0.921 \\
\hline
\end{tabular}

Data for continuous variables are shown as medians (min-max). For co-morbidities, the respective numbers of affected participants were determined at the medical entrance examination. Obesity was defined as a BMI of $>30 \mathrm{~kg} / \mathrm{m}^{2}$. Differences between groups were determined by Mann-Whitney $\mathrm{U}$ or $X^{2}$ tests; significant differences are marked in bold

caloric reduction. Although it is known that resistance training does not promote clinically significant weight loss, it influences body composition by increasing muscle mass and decreasing body fat [34, 35]. Thus, it has been hypothesised that muscle-strengthening exercises also exert anti-inflammatory effects. Based on intervention studies investigating the effects of strength training on inflammatory markers such as CRP, TNF- $\alpha$ and IL-6, the data are ambiguous because some studies have revealed a positive effect $[23,36]$, whereas others did not observe any amelioration in the inflammatory state $[24,25,37]$. While the TGF- $\beta$ superfamily has been studied extensively in the adaptation of muscles and tendons to exercise [38], investigations into the context of exercise immunology are scarce. Our data are in line with a previous study showing that strength training does not alter the level of circulating TGF- $\beta$ [39]. Another study, investigating the influence of a combined strength and endurance exercise programme in type 2 diabetic patients revealed an increase in circulating TGF- $\beta$ [36], but study population and training programme were different making a direct comparison difficult. Nevertheless, in our study, parameters measuring aerobic fitness and muscular endurance, but not handgrip strength, correlated negatively with TGF- $\beta$ alterations. This could hint to the fact that endurance training is an important component of an exercise intervention to target circulating TGF- $\beta$ levels, but further studies are needed to clearly identify the underlying associations.

While circulating levels of TGF- $\beta$ were unaffected, our data revealed that resistance training seems to lower the TGF-BRI mRNA expression in PBMCs of older adults, potentially leading to decreased signalling through the type I receptor. Furthermore, higher levels of TGF- $\beta$ R1 mRNA were detected in the less fit dropouts. As the mRNA was extracted from isolated PBMCs which include lymphocytes and monocytes, but not neutrophils or erythrocytes, it is very unlikely that the observed alterations in TGF- $\beta$ RI mRNA are directly caused by varying neutrophil counts between groups. However, due to the pleiotropic effects of TGF- $\beta$, it is difficult to interpret the clinical implication of these findings. While TGF- $\beta$ signalling is essential for regulatory $\mathrm{T}\left(\mathrm{T}_{\text {reg }}\right)$ cell maturation and immune homeostasis [40, 41], excessive signalling may lead to dysregulated $\mathrm{T}_{\text {Reg }}$ cell activity and may underlie a diverse range of allergic diseases in humans $[42,43]$. Drugs which aim to block the TGF- $\beta$ signalling are under investigation in connection with several disorders such as hypertrophic cardiomyopathy [44], hypertension [45] or the Marfan syndrome [46] and are suggested to be valuable for treating food allergies [42]. Therefore, the observed alterations in TGF- $\beta$ RI mRNA expression caused by resistance training could be beneficial in these situations, whereby future studies need to clarify whether lower mRNA levels de facto lead 
Table 3 Intervention effects on leukocyte subpopulations and circulating inflammatory markers

\begin{tabular}{|c|c|c|c|c|}
\hline & Baseline $(n=67)$ & 3 months $(n=67)$ & 6 months $(n=67)$ & $P$-value (time) \\
\hline \multicolumn{5}{|c|}{ Leukocytes $\left[\times 10^{9}\right.$ cells/L] } \\
\hline$C T(n=26)$ & $7.2(4.9-10.3)^{* *}$ & $7.2(4.1-11.9)$ & $7.1(5.4-9.4)$ & 0.440 \\
\hline $\mathrm{RT}(n=20)$ & $5.6(3.1-9.1)$ & $6.0(3.2-8.9)$ & $6.0(3.3-9.8)^{*}$ & 0.001 \\
\hline RTS $(n=21)$ & $7.0(4.4-13.3)^{* *}$ & $7.2(4.5-11.7)^{* *}$ & $7.1(4.7-13.0)$ & 0.586 \\
\hline \multicolumn{5}{|c|}{ 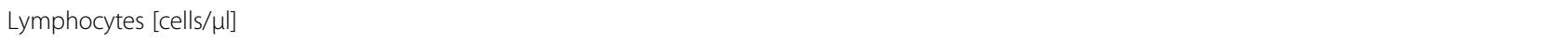 } \\
\hline $\mathrm{CT}(n=26)$ & 1985 (910-3510) & $2090(890-3980)$ & $2250(930-3540)$ & 0.387 \\
\hline $\mathrm{RT}(n=20)$ & $1675(830-3330)$ & $1765(912-3190)$ & 1720 (1010-3430) & 0.651 \\
\hline RTS $(n=21)$ & 2255 (1460-4700) & 2340 (1570-4680) & 2190 (1640-4930) & 0.810 \\
\hline \multicolumn{5}{|c|}{ Monocytes [cells/ul] } \\
\hline $\mathrm{CT}(n=26)$ & $610(72-950)$ & $550(300-780)$ & 590 (400-910) & 0.534 \\
\hline $\mathrm{RT}(n=20)$ & $520(260-790)$ & 475 (250-960) & $510(250-880)$ & 0.104 \\
\hline RTS $(n=21)$ & $585(320-960)$ & $490(300-840)$ & 545 (330-900) & 0.404 \\
\hline \multicolumn{5}{|c|}{ 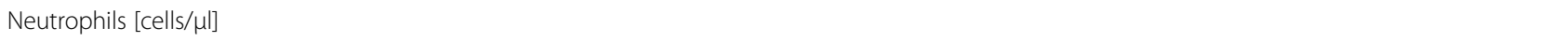 } \\
\hline$C T(n=26)$ & $4300(2410-6630)^{* *}$ & $4010(1990-7420)$ & 3910 (3110-5880) & 0.247 \\
\hline $\mathrm{RT}(n=20)$ & 2876 (1530-6800) & $3390(1720-5880)$ & $3520(1800-7330)^{*}$ & 0.011 \\
\hline RTS $(n=21)$ & 4030 (2430-9860) & 3930 (1720-8730) & 4290 (1664-8680) & 0.368 \\
\hline \multicolumn{5}{|c|}{ 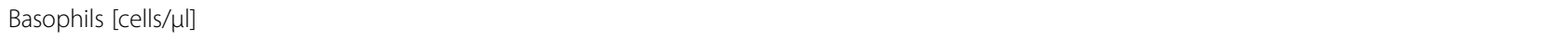 } \\
\hline $\mathrm{CT}(n=26)$ & $40(20-111)$ & $30(10-90)$ & $30(20-100)$ & 0.027 \\
\hline $\mathrm{RT}(n=20)$ & 35 (10-90) & $30(10-100)$ & $30(10-80)$ & 0.878 \\
\hline RTS $(n=21)$ & 40 (10-90) & 40 (10-90) & $40(10-80)$ & 0.344 \\
\hline \multicolumn{5}{|c|}{ 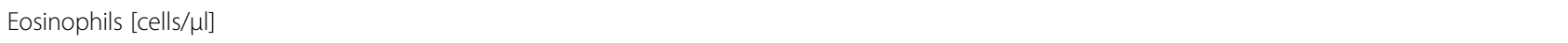 } \\
\hline $\mathrm{CT}(n=26)$ & $210(36-448)$ & $170(80-470)$ & $220(90-330)$ & 0.911 \\
\hline $\mathrm{RT}(n=20)$ & $160(10-690)$ & $186(40-530)$ & $200(80-570)$ & 0.381 \\
\hline RTS $(n=21)$ & $248(90-470)$ & $195(20-630)$ & $260(90-650)$ & 0.137 \\
\hline \multicolumn{5}{|l|}{ hs-CRP [mg/L] } \\
\hline $\mathrm{CT}(n=26)$ & $2.0(0.5-4.8)$ & $2.4(0.2-5.5)$ & $1.8(0.3-8.5)$ & 0.424 \\
\hline $\mathrm{RT}(n=20)$ & $1.9(0.3-7.6)$ & $2.4(0.5-7.7)$ & $2.0(0.6-9.6)$ & 0.645 \\
\hline RTS $(n=21)$ & $1.8(0.6-5.4)$ & $2.1(0.6-8.5)$ & $1.6(0.4-5.5)$ & 0.135 \\
\hline \multicolumn{5}{|l|}{ TGF- $\beta[\mu \mathrm{g} / \mathrm{L}]$} \\
\hline $\mathrm{CT}(n=26)$ & $36.0(18.7-73.7)$ & $39.8(18.4-67.8)$ & $40.8(21.9-67.9)$ & 0.953 \\
\hline $\mathrm{RT}(n=20)$ & $31.5(16.7-50.0)$ & $34.5(18.3-59.7)$ & $34.6(12.7-57.3)$ & 0.075 \\
\hline RTS $(n=21)$ & $33.7(21.0-51.2)$ & $38.0(22.9-50.5)$ & $35.5(22.1-52.1)$ & 0.431 \\
\hline
\end{tabular}

Data are expressed as medians (min-max); Differences over the time course were detected using the Friedman test and if significant, followed by Bonferroni-corrected post-hoc analyses ( ${ }^{*} p<0.05$ vs. baseline within respective study group). Differences between groups were analysed by Kruskal Wallis test, followed by Bonferroni-corrected post-hoc analyses ( ${ }^{* *} p<0.05$ vs. RT group within respective time point; significant differences are marked in bold) $A b b r e v i a t i o n s: C T$ cognitive training, $R T$ resistance training, $R T S$ resistance training plus supplement, $h s-C R P$ high sensitive C-reactive protein, TGF- $\beta$ transforming growth factor- $\beta$

to a lower expression of the receptor on the surface of the respective cells and whether these changes are clinically relevant.

It has to be mentioned that the median TGF- $\beta R 1$ mRNA expression was slightly lower in both, the RT and the RTS group $(-14 \%$ and $-16 \%$, respectively), but reached significance only in the RT group. For physical performance (chair stand and arm lifting performance) similar gains could be detected in both groups. A recent systematic review demonstrated that combining protein supplementation with resistance training is effective for eliciting gains in fat-free mass among older adults, but does not appear to further increase muscle mass or strength, which was similar to our study [47]. In addition to proteins, the supplement in this study contained several vitamins. Based on previous analyses, this supplement aids to increase the uptake of vitamin $D$ and folic acid as well as the plasma levels of vitamin $B_{12}$ and folic acid in erythrocytes $[48,49]$. As some of the variables in this study (TGF- $\beta R I$ mRNA expression, leukocyte 
Table 4 Intervention effects on TGF- $\beta$ signalling gene expression

\begin{tabular}{|c|c|c|c|c|}
\hline & Baseline $(n=67)$ & 3 months $(n=67)$ & 6 months $(n=67)$ & $P$-value (time) \\
\hline \multicolumn{5}{|c|}{ TGF- $\beta / G A P D H ~[-]$} \\
\hline$C \top(n=21)$ & $0.47(0.23-2.66)$ & $0.47(0.27-4.10)$ & $0.44(0.25-1.93)$ & 0.772 \\
\hline $\mathrm{RT}(n=26)$ & $0.54(0.26-2.30)$ & $0.52(0.16-2.63)$ & $0.52(0.23-2.30)$ & 0.568 \\
\hline RTS $(n=20)$ & $0.55(0.06-1.63)$ & $0.45(0.15-2.20)$ & $0.56(0.09-1.32)$ & 0.692 \\
\hline \multicolumn{5}{|c|}{ TGF-ßRI/GAPDH [-] } \\
\hline$C \top(n=21)$ & $1.99(0.14-22.39)$ & $1.62(0.46-29.89)$ & $1.97(0.11-9.24)$ & 0.717 \\
\hline $\mathrm{RT}(n=26)$ & $1.87(0.69-9.54)$ & $1.61(0.34-9.21)^{*}$ & $1.77(0.54-15.91)$ & 0.006 \\
\hline RTS $(n=20)$ & $1.95(0.30-8.63)$ & $1.63(0.28-8.59)$ & $2.38(0.52-6.73)$ & 0.801 \\
\hline \multicolumn{5}{|c|}{ TGF- $\beta$ RII/GAPDH [-] } \\
\hline $\mathrm{CT}(n=21)$ & $1.54(0.66-7.79)$ & $1.39(0.68-9.17)$ & $1.48(0.67-6.32)$ & 0.827 \\
\hline $\mathrm{RT}(n=26)$ & $1.60(0.66-14.86)$ & $1.59(0.57-13.50)$ & $1.67(0.63-8.79)$ & 0.296 \\
\hline RTS $(n=20)$ & $1.58(0.51-5.13)$ & $1.73(0.44-3.98)$ & $1.95(0.69-4.73)$ & 0.331 \\
\hline \multicolumn{5}{|c|}{ miRNA-21 [copies/pg RNA] } \\
\hline $\mathrm{CT}(n=21)$ & $3163(343-4500)$ & $2840(276-5120)$ & $2460(1050-4700)$ & 0.861 \\
\hline $\mathrm{RT}(n=26)$ & $2602(57-4720)$ & $2340(758-5600)$ & $2540(330-5020)$ & 0.368 \\
\hline RTS $(n=20)$ & $2536(845-4590)$ & $2535(353-4780)$ & $2810(1600-4630)$ & 0.854 \\
\hline
\end{tabular}

Data are expressed as medians (min-max); Differences were detected using the Friedman test and if significant, followed by Bonferroni-corrected post-hoc analyses (* $p<0.05$ vs. baseline; significant differences are marked in bold)

Abbreviations: CT cognitive training, RT resistance training, RTS resistance training plus supplement, TGF- $\beta$ transforming growth factor- $\beta$, TGF- $\beta R$ TGF- $\beta$ receptor, GAPDH glyceraldehyde 3-phosphate dehydrogenase, miR-21 microRNA-21

numbers, 6MWT) were altered in the RT but not in the RTS group, it seems that the supplement prevented some of the responses to exercise. There is an ongoing discussion whether antioxidant supplementation may even blunt an exercise-induced training effect [50]. Evidence indicates that reactive oxygen species modulate TGF- $\beta$ signalling. In turn, TGF- $\beta$ increases the production of reactive oxygen species and suppresses antioxidant enzymes [51]. Therefore, it cannot be excluded that rigorous scavenging of free radicals impaired the TGF- $\beta$ pathway response in the RTS group.

A reduction in TGF- $\beta$ RI expression can be caused by either lower production or an increase in degradation of its mRNA. Post-transcriptional degradation of mRNAs often involves miRNAs specific for the respective target gene [12]. We have investigated miRNA-21 that has been shown to suppress TGF- $\beta$ RI and TGF- $\beta$ RII [16]. Additionally, circulating miRNA-21 levels are increased in men with a low aerobic capacity as measured by maximal oxygen uptake [52]. However, its levels were not enhanced in RT or RTS groups, suggesting that other mechanisms and/or other miRNAs are involved in the down-regulation of TGF- $\beta$ RI in PBMCs by strength training [53].

One striking secondary outcome of this study is that TGF- $\beta$, TGF- $\beta$ RI and potentially TGF- $\beta$ RII mRNA expression at the beginning of the study were higher in drop-outs compared with finishers, while miRNA-21 expression was lower. Drop-outs were less physically fit than finishers. We confirmed that age, sex, body composition and the presence of several co-morbidities might not contribute to this effect, but the proportion of subjects with hyperlipidaemia was higher among finishers.

Although this study provides interesting data on TGF$\beta$-related parameters in the context of inflammaging and

Table 5 Association between physical performance at baseline and the response of TGF- $\beta$-related parameters

\begin{tabular}{|c|c|c|c|c|c|}
\hline & & \multicolumn{4}{|c|}{ Baseline performance } \\
\hline & & Handgrip strength & Chair stand test & Arm lifting test & 6-MWT \\
\hline \multirow{5}{*}{$\begin{array}{l}\text { Change (difference between } \\
3 \text { months and baseline) }\end{array}$} & Circulating TGF- $\beta$ & -0.039 & $-0.349 *$ & $-0.352^{*}$ & $-0.308^{*}$ \\
\hline & TGF- $\beta / G A P D H$ & 0.103 & 0.220 & -0.051 & 0.199 \\
\hline & TGF- $\beta$ RI/GAPDH & 0.222 & 0.222 & -0.148 & 0.148 \\
\hline & TGF- $\beta$ RII/GAPDH & 0.142 & $0.254^{*}$ & -0.027 & 0.204 \\
\hline & miRNA-21 & 0.201 & 0.143 & -0.029 & 0.038 \\
\hline
\end{tabular}


exercise training, we also have to highlight some of its limitations. Because the study is a secondary analysis of a previously conducted trial [22], it is obvious that the data need to be confirmed in a future prospective study. Similar to other studies, we were interested in additive effects of the nutritional supplement to strength training rather than investigating the effects of the supplement alone. While this approach represents a best practice model in exercise nutrition, this study design has a limited explanatory power in describing the observed differences between the RT and RTS groups. Finally, the number of female participants outnumbered the male participants by a significant degree. It also has to be mentioned that the proportion of community-dwelling men at an age of 85 years in Vienna is 34\% [54], but the proportion of male individuals in Viennese retirement homes is $19 \%$ for this age group [55] making our study population representative in terms of sex distribution of institutionalised older individuals in Austria. Although it was not possible to perform sub-group analyses because of the low numbers of men, their exclusion led to the same conclusion, indicating that the data are reliable at least for older women.

\section{Conclusions}

Resistance training is beneficial, even in very old subjects, and potentially influences TGF- $\beta$ signalling through altered receptor mRNA expression. Furthermore, adherence to the intervention was significantly related to alterations in the TGF- $\beta$ pathway at baseline, but further information is needed to clearly understand the role of TGF- $\beta$ in the context of inflammaging, resistance training and nutritional supplementation.

\section{Methods}

\section{Participants and study design}

The study was conducted using a randomised observerblind design with three parallel groups, RT, RTS and CT. Briefly, participants were untrained, over 65 years of age with a Mini-Mental State Examination score of $\geq 23$ and free of any medical conditions that would impair their participation in a resistance training study [56]. From a total of 117 participants in the VAAS, only those with available blood samples and a hs-CRP level below $10 \mathrm{mg} / \mathrm{L}$ at any time point were included in the current study $(n=88)$. A detailed description of the study design has been published previously [22].

\section{Interventions}

Interventions were conducted for 6 months, and measurements were obtained at baseline, after 3 and 6 months. Twice a week, RT and RTS groups performed supervised progressive resistance training without using any equipment other than elastic bands and their own body weight.
Each exercise session consisted of a general warm-up of $10 \mathrm{~min}$, followed by a resistance training session (35-40 $\mathrm{min}$ ) incorporating one to two exercises for each of the six main muscle groups (legs, back, abdomen, chest, shoulder and arms), and was completed by a cool-down routine. Following an adaptation phase of 4 weeks using low external resistance (yellow TheraBand $^{\circ}, 1$ set of 15 repetitions per exercise with a higher resistance only if the subject was obviously unchallenged) exercise intensity was progressively increased by changing the Thera-Band ${ }^{\circ}$ from yellow to red and further to black. Additionally, the exercise volume was enhanced by increasing the number of sets from one to two. Rate of progression was based on individual improvements (band colour was changed if participant would have been able to perform two more repetitions in the second set. A detailed description has been provided previously [22]. Additionally to the exercises, participants from the RTS group were encouraged to drink a supplement that was distributed every morning as well as directly after the resistance training (in total nine times per week). One portion consisted of $20.7 \mathrm{~g}$ protein (55 En \%; $19.7 \mathrm{~g}$ whey protein containing more than $10 \mathrm{~g}$ essential amino acids including $3 \mathrm{~g}$ leucine), $9.4 \mathrm{~g}$ carbohydrates (25 En \%), $3.0 \mathrm{~g}$ fat (18 En \%), $1.2 \mathrm{~g}$ fibre (2 En \%), various vitamins such as $800 \mathrm{IU}(20 \mu \mathrm{g})$ vitamin D, minerals and trace elements (FortiFit; Nutricia $\mathrm{GmbH}$, Vienna, Austria). Total energy per drink was $150 \mathrm{kcal}$. Intake of the nutritional supplement was controlled at breakfast as well as after each training session. The CT group served as a control group and performed activities based on cognitive tasks (memory training) and coordinative tasks (such as manual dexterity) twice weekly to provide a timely effort which was equal to those of the RT and RTS groups, respectively $[22,57]$.

\section{Determination of body composition, physical fitness and health}

Standing height was assessed using a commercial stadiometer (Seca, Hamburg, Germany), Body mass was evaluated with a digital scale (BWB 700; Tanita, Amsterdam, Netherlands) to the nearest $0.1 \mathrm{~kg}$ with subjects lightly dressed and barefoot. BMI was calculated by dividing the body mass in kilograms by height in meters squared. To measure strength of the upper extremities, participants performed two trials of an isometric handgrip strength test $(\mathrm{kg})$ using a dynamometer (JAMAR compatible handgrip dynamometer adapted to handle various hand sizes) in a sitting position with an angle of $90^{\circ}$ in the elbow [58]. Functional performance of the lower extremities was measured by a chair stand test, and that of the upper extremities by an arm-lifting test as described previously $[22,59]$. Aerobic capacity was assessed by the $6 \mathrm{MWT}$ conducted on a $30-\mathrm{m}$ shuttle track [60]. 
Global cognitive function was determined by the MiniMental State Examination [61]. Co-morbidities (hyperlipidaemia, hypertension, osteoporosis, cardiac diseases, history of cancer and diabetes mellitus) were determined at the medical entrance examination. Adiposity was defined by a BMI of $>30 \mathrm{~kg} / \mathrm{m}^{2}$ according to the World Health Organization criteria.

\section{Blood sampling and analyses}

After overnight fasting, venous blood samples were obtained in a resting state between 06:30 and 08:00 using Z serum Clot Activator collection tubes (Vacuette; Greiner Bio-One GmbH, Kremsmünster, Austria) to analyse circulating TGF- $\beta$ and hs-CRP, EDTA tubes (Vacuette; Greiner Bio-One $\mathrm{GmbH}$ ) to determine leukocyte subpopulations and BD Vacutainer ${ }^{\circ}$ CPT Tubes (Becton, Dickenson and Company, Schwechat, Austria) containing 130 IU $\mathrm{Na}$-Heparin and $2 \mathrm{~mL}$ Ficoll $^{\text {Tw }}$ to isolate PBMCs.

Hs-CRP was quantified on a Cobas 8000 (Roche Diagnostics, Vienna, Austria). Leukocyte subpopulations were determined by flow cytometric analyses on a XE-2100 automated hematology system (Sysmex Austria GmbH, Vienna, Austria). TGF- $\beta$ was analysed using a commercially available DuoSet development kit to perform an enzyme-linked immunosorbent assay (DY240; R\&D Systems, Abingdon, UK) following the manufacturer's instructions including plasma activation by acidification $(\mathrm{pH} 2)$ by adding hydrochloric acid (final concentration: $0.1 \mathrm{mmol} / \mathrm{L}$ ) and neutralisation with sodium hydroxide (final concentration: $0.12 \mathrm{mmol} / \mathrm{L}$ ) before measurement.

PBMCs were separated from red blood cells and neutrophils using BD Vacutainer ${ }^{\circ}$ CPT Tubes (Becton Dickinson Austria, Vienna, Austria). The obtained pellet was carefully resuspended in $700 \mu \mathrm{L}$ QIAzol Lysis Reagent (Qiagen, Hilden, Germany) and stored at $-80{ }^{\circ} \mathrm{C}$ until analysis.

Total RNA including small RNAs was isolated using a miRNeasy Mini Kit (Qiagen, Hilden, Germany) following the supplier's protocol. To prepare a miRNA-enriched fraction separated from the larger RNAs (>200 nt), we used an RNeasy MinElute Cleanup Kit (Qiagen). Reverse transcription of the miRNA-enriched fraction was performed using a miScript II RT Kit (Qiagen), whereas larger RNAs were reverse transcribed using a QuantiTect Reverse Transcription Kit (Qiagen).

TGF- $\beta$, TGF- $\beta$ RI and TGF- $\beta$ RII mRNA levels were determined using the respective primer pairs [Hs_TGFB1_1 (QT00000728), Hs_TGFBR1_1 (QT00083412) and Hs_TGFBR2_1 (QT00014350); Qiagen] in conjunction with a QuantiTect SYBR Green PCR kit (Qiagen). In addition, glyceraldehyde-3-phosphate dehydrogenase [Hs_GAPDH_2 (QT01192646)] served as the endogenous control to normalise the data. Quantification was performed on an Applied Biosystems ${ }^{\circ} 7500$ Real-Time PCR System.
MiRNA-21 expression levels were detected using a miScript Primer Assay specific for miRNA-21 [hs_miR21_2 (MS00009079); Qiagen]. Quantification was performed on the Applied Biosystems 7500 Real-Time PCR System.

\section{Statistical analyses}

Data acquisition and processing were performed using commercial software (IBM SPSS 20). The Shapiro-Wilk test was used to test for a normal distribution. Because most of the variables were not distributed normally, the non-parametric Mann-Whitney $U$-test or the KruskalWallis test were used to compare two or more independent groups, whereas the Friedman test was applied to detect changes over time in different intervention groups. To avoid bias by multiple testing, the results were Bonferroni-corrected for post-hoc analyses. Correlations between variables were identified by Spearman's rank correlation coefficient. Data are shown as the median (minimum-maximum). Statistical significance was set at $p<0.05$.

\section{Abbreviations}

BMI, body mass index; $C T$, cognitive training; GAPDH, glyceraldehyde 3-phosphate dehydrogenase; hs-CRP, high sensitive C-reactive protein; IL-6, interleukin-6; miRNA, microRNAv; PBMCs, peripheral mononuclear cells; RT, resistance training; RTS, resistance training plus nutritional supplementation; TGF- $\beta$, transforming growth factor- $\beta$; TGF- $\beta R$, TGF- $\beta$ receptor; TNF- $\alpha$, tumour necrosis factor- $\alpha$; $T_{\text {reg, }}$ regulatory T cells; VAAS, Vienna Active Ageing Study

\section{Acknowledgements}

Not applicable.

\section{Funding}

The study was conducted with internal financial support from the University of Vienna, which enabled the establishment of the Research Platform "Active Ageing" as a means to foster interdisciplinary research. The University of Vienna was neither involved in designing the study nor in collecting, analysing and interpreting the data.

\section{Authors' contributions}

$\mathrm{BSH}, \mathrm{MH}, \mathrm{SO}, \mathrm{BF}$ and TW were responsible for data acquisition, data analysis and interpretation of the data. BSH drafted the manuscript. EMS, MQ and NB were responsible for all medical aspects in the study. BW and KHW were involved in the conception and design of the study. BW supervised all aspects of laboratory analyses. All authors were involved in revising the manuscript and approved the final version.

\section{Competing interests}

The authors declare that they have no competing interests.

\section{Consent for publication}

Not applicable.

\section{Ethics approval and consent to participate}

The present study was conducted in accordance with Austrian laws, including the Doctors Act, the Data Protection Act and the Declaration of Helsinki as revised in Edinburgh (2000), and in analogous accordance with International Conference on Harmonization - Good Clinical Practice Guidelines. Written informed consent was obtained from all participants. This study was approved by the ethics committee of the City of Vienna, Austria (EK-11-151-0811) and is registered at ClinicalTrials.gov, NCT01775111. 


\section{Author details}

${ }^{1}$ Research Platform Active Ageing, University of Vienna, Althanstraße 14, 1090 Vienna, Austria. ${ }^{2}$ Department of Sports and Exercise Physiology, Centre for Sport Science and University Sports, University of Vienna, Auf der Schmelz 6, 1150 Vienna, Austria. ${ }^{3}$ Karl Landsteiner Institute for Remobilization and Functional Health/Institute for Physical Medicine and Rehabilitation, Kaiser Franz Joseph Hospital, Social Medical Centre - South, Kundratstrasse 3, 1100 Vienna, Austria. ${ }^{4}$ Department of Nutritional Sciences, Faculty of Life Sciences, University of Vienna, Althanstraße 14, 1090 Vienna, Austria.

\section{Received: 18 February 2016 Accepted: 29 June 2016} Published online: 30 June 2016

\section{References}

1. World Health Organization. World report on ageing and health. Luxembourg. 2015. http://apps.who.int/iris/bitstream/10665/186463/1/ 9789240694811_eng.pdf?ua=1. Accessed 29 June 2016.

2. Pera A, Campos C, Lopez N, Hassouneh F, Alonso C, Tarazona R, et al. Immunosenescence: Implications for response to infection and vaccination in older people. Maturitas. 2015;82(1):50-5. doi:10.1016/j.maturitas.2015.05.004.

3. Pawelec G, Goldeck D, Derhovanessian E. Inflammation, ageing and chronic disease. Curr Opin Immunol. 2014;29:23-8. doi:10.1016/j.coi.2014.03.007.

4. Ceco E, McNally EM. Modifying muscular dystrophy through transforming growth factor-beta. FEBS J. 2013;280(17):4198-209. doi:10.1111/febs.12266.

5. Romano M, Guagnano MT, Pacini G, Vigneri S, Falco A, Marinopiccoli M, et al. Association of inflammation markers with impaired insulin sensitivity and coagulative activation in obese healthy women. J Clin Endocrinol Metab. 2003;88(11):5321-6. doi:10.1210/jc.2003-030508.

6. Agarwal I, Glazer NL, Barasch E, Biggs ML, Djousse L, Fitzpatrick AL, et al. Fibrosis-related biomarkers and incident cardiovascular disease in older adults: the cardiovascular health study. Circ Arrhythm Electrophysiol. 2014; 7(4):583-9. doi:10.1161/CIRCEP.114.001610.

7. Pfeiffer A, Middelberg-Bisping K, Drewes C, Schatz H. Elevated plasma levels of transforming growth factor-beta 1 in NIDDM. Diabetes Care. 1996;19(10):1113-7.

8. Esmatjes E, Flores L, Lario S, Claria J, Cases A, Inigo P, et al. Smoking increases serum levels of transforming growth factor-beta in diabetic patients. Diabetes Care. 1999;22(11):1915-6.

9. Lin Y, Nakachi K, Ito Y, Kikuchi S, Tamakoshi A, Yagyu K, et al. Variations in serum transforming growth factor-beta1 levels with gender, age and lifestyle factors of healthy Japanese adults. Dis Markers. 2009;27(1):23-8. doi:10.3233/DMA-2009-0643.

10. Blank U, Karlsson S. TGF-beta signaling in the control of hematopoietic stem cells. Blood. 2015;125(23):3542-50. doi:10.1182/blood-2014-12-618090.

11. Lewis BP, Burge CB, Bartel DP. Conserved seed pairing, often flanked by adenosines, indicates that thousands of human genes are microRNA targets. Cell. 2005;120(1):15-20. doi:10.1016/j.cell.2004.12.035.

12. Guo H, Ingolia NT, Weissman JS, Bartel DP. Mammalian microRNAs predominantly act to decrease target mRNA levels. Nature. 2010;466(7308): 835-40. doi:10.1038/nature09267.

13. Griffiths-Jones S. miRBase: the microRNA sequence database. Methods Mol Biol. 2006;342:129-38. doi:10.1385/1-59745-123-1:129.

14. Kozomara A, Griffiths-Jones S. miRBase: annotating high confidence microRNAs using deep sequencing data. Nucleic Acids Res. 2014; 42(Database issue):D68-73. doi:10.1093/nar/gkt1181.

15. Kumarswamy R, Volkmann I, Thum T. Regulation and function of miRNA-21 in health and disease. RNA Biol. 2011;8(5):706-13. doi:10.4161/rna.8.5.16154

16. Olivieri F, Spazzafumo L, Santini G, Lazzarini R, Albertini MC, Rippo MR, et al. Age-related differences in the expression of circulating microRNAs: miR-21 as a new circulating marker of inflammaging. Mech Ageing Dev. 2012; 133(11-12):675-85. doi:10.1016/j.mad.2012.09.004.

17. Ando Y, Yang GX, Kenny TP, Kawata K, Zhang W, Huang W, et al. Overexpression of microRNA-21 is associated with elevated pro-inflammatory cytokines in dominant-negative TGF-beta receptor type II mouse. J Autoimmun. 2013;41:111-9. doi:10.1016/j.jaut.2012.12.013.

18. Mathur N, Pedersen BK. Exercise as a mean to control low-grade systemic inflammation. Mediators Inflamm. 2008;2008:109502. doi:10.1155/2008/109502.

19. Ryan AS, Ge S, Blumenthal JB, Serra MC, Prior SJ, Goldberg AP. Aerobic exercise and weight loss reduce vascular markers of inflammation and improve insulin sensitivity in obese women. J Am Geriatr Soc. 2014;62(4): 607-14. doi:10.1111/jgs.12749.
20. Mikkelsen UR, Couppe C, Karlsen A, Grosset JF, Schjerling P, Mackey AL, et al. Life-long endurance exercise in humans: circulating levels of inflammatory markers and leg muscle size. Mech Ageing Dev. 2013;134(11-12):531-40. doi:10.1016/j.mad.2013.11.004.

21. Peterson MD, Sen A, Gordon PM. Influence of resistance exercise on lean body mass in aging adults: a meta-analysis. Med Sci Sports Exerc. 2011:43(2): 249-58. doi:10.1249/MSS.0b013e3181eb6265.

22. Oesen S, Halper B, Hofmann M, Jandrasits W, Franzke B, Strasser EM, et al. Effects of elastic band resistance training and nutritional supplementation on physical performance of institutionalised elderly - A randomized controlled trial. Exp Gerontol. 2015;72:99-108. doi:10.1016/j.exger.2015.08.013.

23. Phillips MD, Patrizi RM, Cheek DJ, Wooten JS, Barbee JJ, Mitchell JB. Resistance training reduces subclinical inflammation in obese, postmenopausal women Med Sci Sports Exerc. 2012;44(11):2099-110. doi:10.1249/MSS. 0b013e3182644984.

24. Bruunsgaard $H$, Bjerregaard $E$, Schroll M, Pedersen BK. Muscle strength after resistance training is inversely correlated with baseline levels of soluble tumor necrosis factor receptors in the oldest old. J Am Geriatr Soc. 2004; 52(2):237-41.

25. Wanderley FA, Moreira A, Sokhatska O, Palmares C, Moreira P, Sandercock G, et al. Differential responses of adiposity, inflammation and autonomic function to aerobic versus resistance training in older adults. Exp Gerontol. 2013;48(3): 326-33. doi:10.1016/j.exger.2013.01.002.

26. Hofmann M, Schober-Halper B, Oesen S, Franzke B, Tschan H, Bachl N, et al. Effects of elastic band resistance training and nutritional supplementation on muscle quality and circulating muscle growth and degradation factors of institutionalized elderly women - the Vienna Active Ageing Study (VAAS) Eur J Appl Physiol. 2016. doi:10.1007/s00421-016-3344-8.

27. Halper B, Hofmann M, Oesen S, Franzke B, Stuparits P, Vidotto C, et al. Influence of age and physical fitness on miRNA-21, TGF-beta and its receptors in leukocytes of healthy women. Exerc Immunol Rev. 2015;21:154-63.

28. Brinkley TE, Leng X, Miller ME, Kitzman DW, Pahor M, Berry MJ, et al. Chronic inflammation is associated with low physical function in older adults across multiple comorbidities. J Gerontol Ser A, Biol Sci Med Sci. 2009;64(4):455-61. doi:10.1093/gerona/gln038

29. Mavros Y, Kay S, Simpson KA, Baker MK, Wang Y, Zhao RR, et al. Reductions in C-reactive protein in older adults with type 2 diabetes are related to improvements in body composition following a randomized controlled trial of resistance training. J Cachex Sarcopenia Muscle. 2014;5(2):111-20. doi:10.1007/s13539-014-0134-1.

30. Jahromi AS, Zar A, Ahmadi F, Krustrup P, Ebrahim K, Hovanloo F, et al. Effects of Endurance Training on the Serum Levels of Tumour Necrosis Factor-alpha and Interferon-gamma in Sedentary Men. Immune Netw. 2014; 14(5):255-9. doi:10.4110/in.2014.14.5.255.

31. Wang $\mathrm{CH}$, Chung MH, Chan P, Tsai JC, Chen FC. Effects of endurance exercise training on risk components for metabolic syndrome, interleukin-6, and the exercise capacity of postmenopausal women. Geriatr Nurs. 2014; 35(3):212-8. doi:10.1016/j.gerinurse.2014.02.001.

32. Czarkowska-Paczek B, Zendzian-Piotrowska M, Bartlomiejczyk I, Przybylski J, Gorski J. The influence of physical exercise on the generation of TGF-beta1, PDGF-AA, and VEGF-A in adipose tissue. Eur J Appl Physiol. 2011;111(5):875-81. doi:10.1007/s00421-010-1693-2.

33. Sallam N, Laher I. Exercise Modulates Oxidative Stress and Inflammation in Aging and Cardiovascular Diseases. Oxid Med Cell Longev. 2016;2016: 7239639. doi:10.1155/2016/7239639.

34. Donnelly JE, Blair SN, Jakicic JM, Manore MM, Rankin JW, Smith BK, et al. American College of Sports Medicine Position Stand. Appropriate physical activity intervention strategies for weight loss and prevention of weight regain for adults. Med Sci Sports Exerc. 2009;41(2):459-71. doi:10.1249/MSS. ob013e3181949333.

35. Miller PE, Alexander DD, Perez V. Effects of whey protein and resistance exercise on body composition: a meta-analysis of randomized controlled trials. J Am Coll Nutr. 2014;33(2):163-75. doi:10.1080/07315724.2013.875365.

36. Touvra AM, Volaklis KA, Spassis AT, Zois CE, Douda HD, Kotsa K, et al. Combined strength and aerobic training increases transforming growth factor-beta1 in patients with type 2 diabetes. Hormones (Athens). 2011;10(2):125-30.

37. Perreault K, Courchesne-Loyer A, Fortier M, Maltais M, Barsalani R, Riesco E, et al. Sixteen weeks of resistance training decrease plasma heat shock protein 72 (eHSP72) and increase muscle mass without affecting high sensitivity inflammatory markers' levels in sarcopenic men. Aging Clin Exp Res. 2015. doi:10.1007/s40520-015-0411-7. 
38. Gumucio JP, Sugg KB, Mendias CL. TGF-beta superfamily signaling in muscle and tendon adaptation to resistance exercise. Exerc Sport Sci Rev. 2015; 43(2):93-9. doi:10.1249/JES.0000000000000041.

39. Bautmans I, Njemini R, Vasseur S, Chabert H, Moens L, Demanet C, et al. Biochemical changes in response to intensive resistance exercise training in the elderly. Gerontology. 2005;51(4):253-65. doi:10.1159/000085122.

40. Sledzinska A, Hemmers S, Mair F, Gorka O, Ruland J, Fairbairn L, et al. TGFbeta signalling is required for CD4(+) T cell homeostasis but dispensable for regulatory T cell function. PLoS Biol. 2013;11(10):e1001674. doi:10.1371/ journal.pbio.1001674.

41. Li MO, Sanjabi S, Flavell RA. Transforming growth factor-beta controls development, homeostasis, and tolerance of T cells by regulatory $T$ celldependent and -independent mechanisms. Immunity. 2006;25(3):455-71. doi:10.1016/j.immuni.2006.07.011.

42. Frischmeyer-Guerrerio PA, Guerrerio AL, Oswald G, Chichester K, Myers L, Halushka MK, et al. TGFbeta receptor mutations impose a strong predisposition for human allergic disease. Sci Transl Med. 2013;5(195): 195ra94. doi:10.1126/scitranslmed.3006448.

43. Bordon Y. Asthma and allergy: TGFbeta-too much of a good thing? Nat Rev Immunol. 2013;13(9):618-9. doi:10.1038/nri3519.

44. Lim DS, Lutucuta S, Bachireddy P, Youker K, Evans A, Entman M, et al. Angiotensin II blockade reverses myocardial fibrosis in a transgenic mouse model of human hypertrophic cardiomyopathy. Circulation. 2001;103(6):789-91.

45. Lavoie P, Robitaille G, Agharazii M, Ledbetter S, Lebel M, Lariviere R. Neutralization of transforming growth factor-beta attenuates hypertension and prevents renal injury in uremic rats. J Hypertens. 2005;23(10):1895-903.

46. Habashi JP, Judge DP, Holm TM, Cohn RD, Loeys BL, Cooper TK, et al. Losartan, an AT1 antagonist, prevents aortic aneurysm in a mouse model of Marfan syndrome. Science. 2006;312(5770):117-21. doi:10.1126/science.1124287.

47. Finger D, Goltz FR, Umpierre D, Meyer E, Rosa LH, Schneider CD. Effects of protein supplementation in older adults undergoing resistance training: a systematic review and meta-analysis. Sports Med. 2015;45(2):245-55. doi:10.1007/s40279-014-0269-4.

48. Franzke B, Halper B, Hofmann M, Oesen S, Jandrasits W, Baierl A, et al. The impact of six months strength training, nutritional supplementation or cognitive training on DNA damage in institutionalised elderly. Mutagenesis. 2015;30(1):147-53. doi:10.1093/mutage/geu074.

49. Franzke B, Halper B, Hofmann M, Oesen S, Pierson B, Cremer A, et al. The effect of six months of elastic band resistance training, nutritional supplementation or cognitive training on chromosomal damage in institutionalized elderly. Exp Gerontol. 2015;65:16-22. doi:10.1016/j.exger.2015.03.001.

50. Peternelj TT, Coombes JS. Antioxidant supplementation during exercise training: beneficial or detrimental? Sports Med. 2011;41(12):1043-69. doi:10.2165/11594400-000000000-00000.

51. Liu RM, Desai LP. Reciprocal regulation of TGF-beta and reactive oxygen species: A perverse cycle for fibrosis. Redox Biol. 2015;6:565-77. doi:10.1016/j.redox.2015.09.009.

52. Bye A, Rosjo H, Aspenes ST, Condorelli G, Omland T, Wisloff U. Circulating microRNAs and aerobic fitness-the HUNT-Study. PLoS One. 2013;8(2):e57496. doi:10.1371/journal.pone.0057496.

53. Stolzenburg LR, Wachtel S, Dang H, Harris A. miR-1343 attenuates pathways of fibrosis by targeting the TGF-beta receptors. Biochem J. 2016;473(3):245-56. doi:10.1042/BJ20150821.

54. Statistik Austria. 2015. Statistik des Bevölkerungsstandes. http://www.statistik. at/web_de/statistiken/menschen_und_gesellschaft/bevoelkerung/ bevoelkerungsstruktur/bevoelkerung_nach_alter_geschlecht/023468.html. Accessed 29 June 2016.

55. Bader E, Graumann G, Hacker M, Heissenberger C, Honeder M, Koblinger N, Krb W, Nutz W, Redolfi T, Scheidl A, Schlöss R, Stieb H, Warmuth $H$. Geschäftsbericht der Häuser zum Leben. 2013. http://www.kwp.at/pics/web/ Dokumente/KWP_gesamt_web_low.pdf. Accessed 29 June 2016.

56. Williams MA, Haskell WL, Ades PA, Amsterdam EA, Bittner V, Franklin BA, et al. Resistance exercise in individuals with and without cardiovascular disease: 2007 update: a scientific statement from the American Heart Association Council on Clinical Cardiology and Council on Nutrition, Physical Activity, and Metabolism. Circulation. 2007;116(5):572-84. doi:10. 1161/CIRCULATIONAHA.107.185214.

57. Gatterer G, Croy A. Geistig fit ins Alter. Vienna: Springer; 2004.

58. Mijnarends DM, Meijers JM, Halfens RJ, ter Borg S, Luiking YC, Verlaan S, et al. Validity and reliability of tools to measure muscle mass, strength, and physical performance in community-dwelling older people: a systematic review. J Am Med Dir Assoc. 2013;14(3):170-8. doi:10.1016/j.jamda.2012.10.009.
59. Jones CJ, Rikli RE, Beam WC. A 30-s chair-stand test as a measure of lower body strength in community-residing older adults. Res Q Exerc Sport. 1999; 70(2):113-9. doi:10.1080/02701367.1999.10608028.

60. Steffen TM, Hacker TA, Mollinger L. Age- and gender-related test performance in community-dwelling elderly people: Six-Minute Walk Test, Berg Balance Scale, Timed Up \& Go Test, and gait speeds. Phys Ther. 2002;82(2):128-37.

61. Folstein MF, Folstein SE, McHugh PR. "Mini-mental state". A practical method for grading the cognitive state of patients for the clinician. J Psychiatr Res. 1975;12(3):189-98.

\section{Submit your next manuscript to BioMed Central and we will help you at every step:}

- We accept pre-submission inquiries

- Our selector tool helps you to find the most relevant journal

- We provide round the clock customer support

- Convenient online submission

- Thorough peer review

- Inclusion in PubMed and all major indexing services

- Maximum visibility for your research

Submit your manuscript at www.biomedcentral.com/submit
C Biomed Central 